\title{
Substance use disorders in Belgium: the need to study rarely investigated high impact disorders
}

by

\author{
Bruffaerts $\mathrm{R}^{1}$
}

Although the problem of substance use disorders in Belgium may be seen as not that important or widespread as in some other developed countries such as the United States or the Middle Americas, statistical evidence from a growing number of epidemiological and clinical studies points to the importance of substance disorders in Belgium. From epidemiological studies it becomes clear that about 8 million Belgians have ever consumed alcohol, about 800,000 cannabis, and 120,000 cocaine (1). Recent epidemiological studies pointed to three critical issues concerning substance use disorders that should be taken into account.

First, although the risk of developing substance use disorders remains generally low among persons who ever used substances (2), the use of substances is a community issue, and is not an isolated phenomenon. After all, the mere use of substances starts at very early ages, with late childhood and adolescence as critical risk periods for developing problematic use (3) and early adolescence as critical periods of developing substance use disorders (4). Following this, the implementation of both information campaigns on and prevention of use for high risk groups may be warranted, as is currently the case within the Flemish political context. It is crucial to study how an evidence-based prevention policy may be best implemented in order to maximize health gains against limited resources (5). In general, there is a lack of European studies in this field, and this emphasizes the strong need for studies on long-term health effects of cannabis use, factors that may stop or delay the transition from cannabis use to cannabis problems, and costs associated with the use of cannabis before an evidence-based strategy may be implemented. In line with this, Godin et al. (6) investigated the effects of mass media campaigns on drug and alcohol consumption in Belgium. Although they found that the campaign was well-appreciated, only $19 \%$ of the respondents recollected the campaign, and not even $4 \%$ was able to name the organizing institution. More importantly, however, persons who did remember the campaign tended to forget the message of the campaign quickly. If we assume that health promotion and prevention of substance use problems may be achievable by, among others, broad dissemination of information on facts, fictions, and risks of the use of substances, well-designed campaigns may be quintessential.

Second, whereas lifetime prevalence (i.e. the proportion of persons who meet criteria for a substance use disorder during lifetime) is estimated at approximately $8 \%$ of the general Belgian population, lifetime risk (i.e. the proportion of persons who will ever meet criteria for a substance use disorder) is estimated at approximately $11 \%$ (4). This means that a consider-

\footnotetext{
Katholieke Universiteit Leuven, Department of Neurosciences, Biomedical Sciences Group, Leuven, Belgium ronny.bruffaerts@med.kuleuven.be
} 
able proportion of the population that, at this point, does not meet criteria for a substance abuse disorder, will eventually develop the disorder when they get older. One implication is that, in general, the proportion of substance use disorders is expected to increase. In addition, especially cohorts born after 1970 are more prone to initiate substances and, eventually, develop substance use disorders (7). Younger cohorts also have higher levels of illegal drug use and women catching up with men (8). That younger cohorts are more prone of developing substance use problems is an important finding for both clinicians and policy makers. In first instance, research will have to investigate specific patterns of substance use among younger cohorts. Rosiers et al. (9) present estimates of stimulant medication use in Flemish students throughout four decades (1965-2005). Past-year use was estimated in the $2.9-5.7 \%$ range, with a trend towards higher use in exam periods, and there were no clear gender differences. Probably the most important finding from this study is that the authors did not find any evidence for an increasing trend of substance use, in contrast to features from the United States (10). Important, however, is the point that medication use in students may be associated with emotional problems. Studying this association could be an important addition to the field that needs to be explored in further research.

A third conclusion from epidemiological research is that the use of services for substance use disorders significantly increased over the past decades but still remains inadequate $(7,11)$. The past decade, there is a trend for science-based treatments gradually becoming more available in clinical settings (12), and specific treatment-related demand research is currently underway. For instance, cannabis-using persons seeking professional treatment consist of a distinct group of persons, not comparable with other substance-using patients (13). Cannabis-using patients were significantly more likely male, young, student, more often living with their parents, and have been in contact with police or justice. Interestingly, they were also significantly less likely to have entered treatment compared to patients using other substances. Once patients have entered treatment, assuming that relapses are the rule rather than the exception in treating substance use disorders is quintessential in fine-tuning treatment resources for substance problems. This becomes even more important when resources for mental health treatments are restricted and lead to further deinstitutionalization of health care. Against this, there is a need towards studies that may elucidate the precise effects of inpatient treatment. Despite the high availability of long-term inpatient treatment opportunities for alcohol patients in Belgium, prospective research is scarce. An exception is Vanderplasschen et al. (14). They found that four in ten patients, six months after discharge from a 3-month treatment program, did not use any alcohol during the follow-up period. By contrast, about six in ten still reported the use of alcohol and one in four had been drinking excessively during the entire follow-up period. One third was readmitted within six months after discharge. Also, patients were in better emotional condition after six months but a similar study (15) found no differences in emotional health six months after discharge from an alcohol treatment program. Evidently, more research is needed in order to elucidate the short- and long-term effects of alcohol treatment, on both the level of substance use as the level of emotional health and comorbid mental disorders. 
The abuse of substances is a widespread, chronic, and high-impact phenomenon. The condition is characterized by a high degree of mental disorders comorbidity. Treatment rates are generally low, and those who enter treatment, oftentimes do not get appropriate treatment. These facts leave open major possibilities for early intervention, primary and secondary prevention programs at both the level of the general population and the level of specific risk groups. In order to develop sustainable policies on the substance abuse issue, countryspecific reports are quintessential. Against this, substance abuse research in Belgium is relatively scarce, too scarce to provide sufficient evidence for informing policy makers as to how, when, or where to (re)allocate financial resources for substance abuse treatment and prevention. We need a better understanding of specific substance abuse patterns, age differences, short- and long-term effects of mere use, misuse, abuse, and dependence. For these reasons, among others, policy makers need to be attentive for the (re)allocation of financial resources that must be devoted in order to install and maintain a long-term substance abuse policy.

\section{References}

1. Degenhardt L, Chiu WT, Sampson N, Kessler RC, Anthony JC, Angermeyer M et al. Toward a global view of alcohol, tobacco, cannabis, and cocaine use: Findings from the WHO World Mental Health Surveys. PLoS Medicine 2008; Jul 1; 5(7): e141

2. Wagner FA, Anthony JC. Into the World of illegal drug use: exposure opportunity and other mechanisms linking the use of alcohol, marijuana, and cocaine. Am J Epidemiol 2002; 155: 918-25

3. Vlaams Agentschap Zorg-en-Gezondheid. Middelengebruik in Vlaanderen. Een stand van zaken. Brussel: Vlaams Agentschap Zorg-en-Gezondheid, 2007

4. Bonnewyn A, Bruffaerts R, Vilagut G, Almansa J, Demyttenaere K. Lifetime risk of mental disorders in the Belgian general population. Social Psychiatry and Psychiatric Epidemiology 2007; 42: 522-9

5. Matthys N, Van Hal G, Beutels P. Evidence-based prevention of cannabis use in Flanders: Is there a role for health economic evaluation? Arch Public Health 2009; 67(4): 146-60

6. Godin I, Dujardin S, Fraeyman J, Van Hal G. Differences on the perception of a mass media information campaign on drug and alcohol consumption. Arch Public Health 2009; 67(4): 161-8

7. Bruffaerts R, Bonnewyn A, Demyttenaere K. Mental Health in Belgium: Current Situation and Future Perspectives. In Kessler RC \& Üstün TB (Eds.). The World Mental Health Survey Initiative Volume One: Patterns of mental illness in the WMH Surveys, pp.279-304. New York: Cambridge University Press, 2008

8. Bruffaerts R, Sabbe M, Demyttenaere K. Patients with substance use disorders in the psychiatric emergency unit, 1999-2008. A ten year perspective. Annual conference of the International Federation of Psychiatric Epidemiology, April 16 -19, 2009, Vienna, Austria

9. Rosiers J, Van Hal G. Stimulant medication use among Flemish students: results from an exploring secondary data analysis 1965-2005. Arch Public Health 2009; 67(4): 169-78

10. National Institute of Drug Abuse (2007)

11. Wang PS, Angermeyer M, Borges G, Bruffaerts R, Chiu WT, de Girolamo G et al. Delay and failure in treatment seeking after first onset of mental disorders in the WHO World Mental Health (WMH) Survey Initiative. World Psychiatry 2007; 6:168-76

12. Miller PM. Evidence-based addiction treatment. New York: Elsevier, 2009 
13. Colpaert K, Vanderplasschen W, Van Hal, Schuyten G, Broekaert E. Cannabis-Related Treatment Demands in Belgium: A Socio-Demographic and Treatment Seeking Profile. Arch Public Health 2009; 67(4): 179-93

14. Vanderplasschen W, Colpaert K, Broekaert Eric. Determinants of relapse and re-admission among alcohol abusers after intensive residential treatment. Arch Public Health 2009; 67(4): 194-211

15. Hermans S, Demyttenaere K, Bruffaerts R. The effects of motivational and case management approaches in the evolution of psychiatric comorbidity in alcohol abusers. An explorative prospective approach. ]Submitted] 